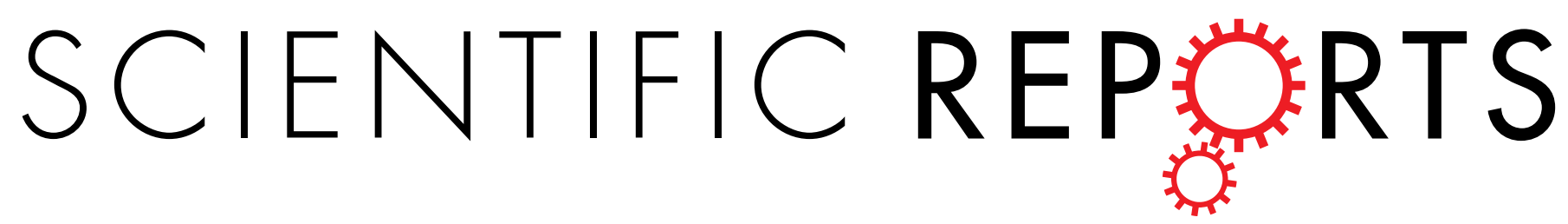

OPEN

\title{
Author Correction: Onion-like networks are both robust and resilient
}

Yukio Hayashi \& Naoya Uchiyama

Published online: 26 September 2018

Correction to: Scientific Reports https://doi.org/10.1038/s41598-018-29626-w, published online 26 July 2018

In Figure 9, the graphs on the Left are incorrect duplications of the graphs in the Middle, in both rows. The correct Figure 9 appears below as Figure 1. 

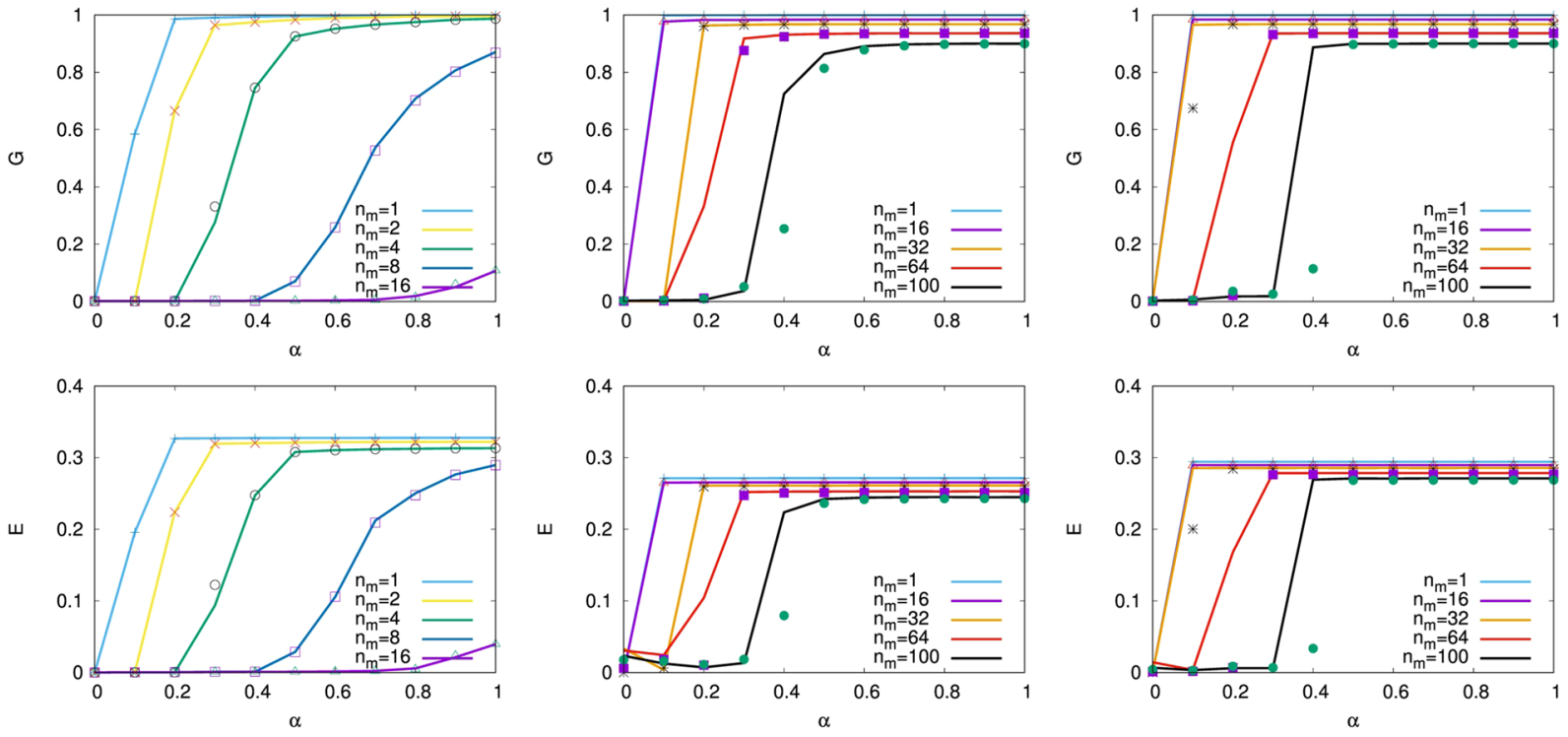

Figure 1. Tolerance against the trigger of multi-attacks for our detour routing on (Left) SF networks, onionlike networks by MED-kmin of (Middle) $\mu=0$, and (Right) $\mu=4$. Line and mark distinguish the cases of simultaneously removing $n_{m}$ nodes selected in decreasing order of degree and load from the maximum, respectively, however there is little difference between them.

(c) (i) Open Access This article is licensed under a Creative Commons Attribution 4.0 International License, which permits use, sharing, adaptation, distribution and reproduction in any medium or format, as long as you give appropriate credit to the original author(s) and the source, provide a link to the Creative Commons license, and indicate if changes were made. The images or other third party material in this article are included in the article's Creative Commons license, unless indicated otherwise in a credit line to the material. If material is not included in the article's Creative Commons license and your intended use is not permitted by statutory regulation or exceeds the permitted use, you will need to obtain permission directly from the copyright holder. To view a copy of this license, visit http://creativecommons.org/licenses/by/4.0/.

(C) The Author(s) 2018 